\title{
Halothane related liver affection in an anaesthetist
}

\author{
S LINGS
}

From the Department of Occupational Medicine, Odense University Hospital, DK-5000 Odense C, Denmark

Halothane has been used as an anaesthetic since the late 1950s; it is normally administered together with laughing gas $\left(\mathrm{N}_{2} \mathrm{O}\right)$ and oxygen, the halothane content of the mixture being around $0 \cdot 5-2.0 \%$ (5000-20 000 $\mathrm{ppm})$. There is strong evidence that halothane is hepatotoxic both in patients who have undergone surgery and animals used for experimental purposes. ${ }^{1-3}$ Repeated exposure at irregular intervals has caused serious liver dysfunction in guinea pigs. ${ }^{4}$ An attempt has been made to determine the extent to which anaesthetists also run the risk of damage to the liver in several clinical and epidemiological surveys. Where findings were positive, the authors have thought that the cause was occupational exposure to halothane, ${ }^{56}$ but since anaesthetists are mostly exposed to a complicated mixture of various substances, the results are difficult to interpret. A few casuistic descriptions of halothane induced occupational liver dysfunction have been published, only two of which concerned anaesthetists. $^{78}$

\section{Case history}

A 54 year old anaesthetist had worked with halothane to an increasing extent since the late 1960s but under good hygienic conditions. In his present position, which he had held since 1974, he had to work in an old building where the rooms were completely without ventilation and where escapes from the anaesthetic systems took place. The anaesthetist, surgeons, and nurses regularly experienced symptoms of slight, acute intoxication (feeling of inebriation, headache, nausea, dizziness). In 1982 he moved to a modern surgical ward that was well ventilated. Nevertheless, after occasional escapes caused by accidents and the use of certain procedures, surgeons and nurses suffered from headaches, nausea, and dizziness and could, for instance, feel the effects for the rest of the day when they had anaesthetised three children by use of face masks. Not until 1986 were funds made available for exhaust equipment for some of these procedures.

In July 1985 the anaesthetist contacted the rheumatological ward because of periodic, painful redness and swelling of the right ankle joint. He had been taking $100 \mathrm{mg}$ of ketoprofen twice daily for the

Accepted 14 September 1987 pain in the ankle joint. Serum urate was raised to 0.49 mmol/l (normally less than 0.43 ), serum creatinine to $132 \mu \mathrm{mol} / \mathrm{l}$ (less than 130), serum carbamide to 12.4 $\mathrm{mmol} / \mathrm{l}$ (less than 8), serum phosphate, non-esterified, to 1.7 (less than 1.6), LDH to 551 (200-450), whereas all other laboratory findings (serum alanine aminotransferase (ALAT), base phosphatase, bilirubin, cholesterol, iron, albumin, sodium, potassium, calcium, sedimentation rate, thrombocytes, haemoglobin, other haematological parameters, creatinine clearance, RAT, and Waaler-Rose) were normal. Gout was diagnosed and treatment with $100 \mathrm{mg}$ of allopurinol, twice daily, was started four days later; after a fortnight all laboratory findings were normal. The patient continued to take $200 \mathrm{mg}$ of sulindac daily. Regular clinical and laboratory tests were henceforth carried out on the patient at intervals of a few weeks. There were few joint symptoms and no side effects from the treatment or other discomfort. From January 1986 intermittent increases in ALAT (see fig) were observed but there were no significant deviations in any of the other laboratory test values and, in particular, there was no increase in other enzyme activity; tests for infectious hepatitis gave negative results. On 13 February sulindac was replaced by 600 $\mathrm{mg}$ of ibuprofen, three times daily, this being discontinued a week later. In the autumn of 1986 he began to suffer from eczema on both hands and spasms of the urinary system (which could have been caused by $\mathrm{N}_{2} \mathrm{O}$ ). As a result, allopurinol was also discontinued at the beginning of November, after which there were no further symptoms. His consumption of alcohol was low.

Increasing ALAT levels were observed in the course of the regular tests at the beginning of 1986 (see fig) and the anaesthetist suspected that this could have been caused by exposure to halothane. He took three weeks holiday from 26 January, and after returning to work completely avoided working with the substance. After this, ALAT activity returned to normal. From the beginning of June 1986 he carried out a provocation test on himself, using halothane for anaesthesia two to four hours a week. All forms of medicine had been discontinued at this time. The ALAT value had risen to 57 by 8 July. The test was therefore discontinued and he has since refrained from working with halothane. Some exposure to air pollution emanating 


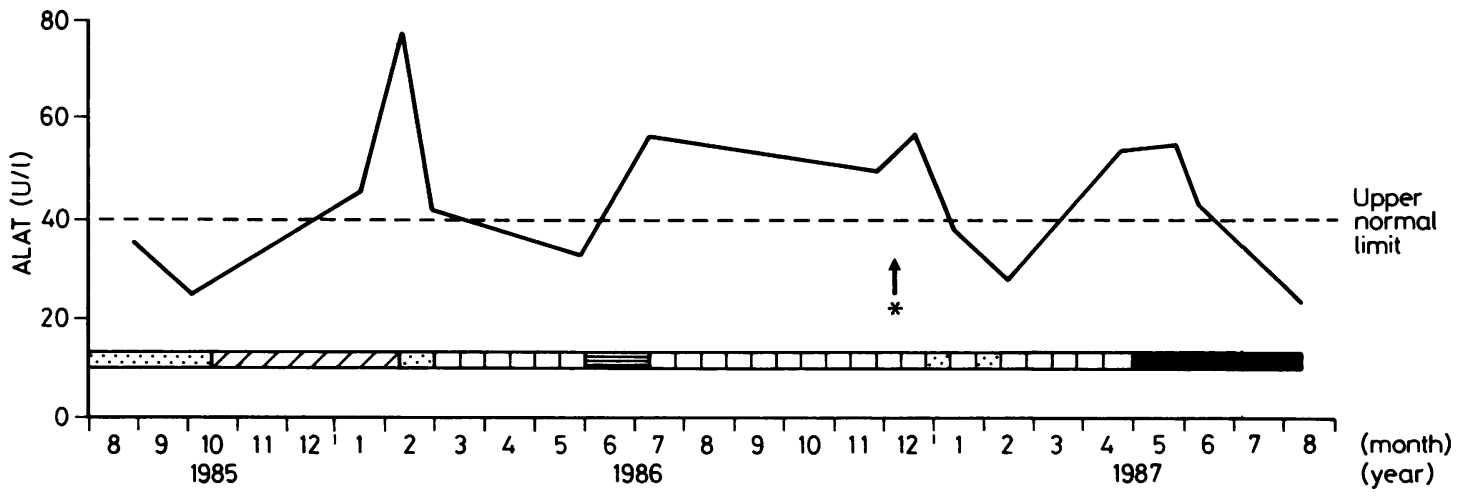

Serum alanine aminotransferase activity during a two year period $\because \cdots$ Holidays. Work without halothane. Provocation test: work with halothane two to four hours weekly. Sick leave. * Leakage from a halothane vaporiser discovered.

from others' working with the substance has however been unavoidable. At the beginning of December 1986 a leakage from the halothane vaporiser in one of the operating theatres where he worked was discovered by chance. ALAT values were normalised at the beginning of 1987 after he had taken a combined Christmas and winter holiday. They rose again after his return to work (he was still taking no form of medication) but returned to normal during the subsequent period when he stayed away from work ("sick leave"). Test results for hepatitis antigens and antibodies were negative and he had no symptoms.

\section{Discussion}

From a chemical and toxicological point of view halothane may be considered an organic solvent. After inspiration, the major part is quickly excreted during respiration but it has been detected in air expired by anaesthetic staff 64 hours after exposure. ${ }^{9}$ A smaller amount (11-25\%) is biotransformed into metabolites, including free radicals, which are excreted in urine over a period of two weeks after entering the body. ${ }^{10}$ Much evidence points to the liver affection associated with repeated exposure being caused by a form of hypersensitivity in which highly reactive metabolites are assumed to play a leading part. ${ }^{3}$ The parenchymal affection is similar to that seen in viral hepatitis. Patients seldom react, however, and the pharmacological and technical properties of halothane are considered so valuable as to outweigh the risk, and in many places it is still the most used anaesthetic, even in operations on the liver. Laughing gas does not appear to be hepatotoxic.
In the case described above alcohol consumption was minimal. As ALAT values rose after exposure to halothane and fell during periods away from work and when deliberate exposure was avoided, it is reasonable to assume that there was a causal connection. The anaesthetist does not wish to take part in further provocation tests and has been continuously away from work for several months for fear of damage to the liver. At present he is considering retirement.

\section{References}

1 Carney FMT, Van Dyke RA. Halothane hepatitis: a critical review. Anesth Analg 1972;51:135-60.

2 Dundee JW, Fee JPH, Mcliroy PDA, Black GW. Prospective study of liver function following repeat halothane and enflurane. J R Soc Med 1981;74:286-91.

3 Anonymous. Halothane-associated liver damage. Lancet 1986;:1251-2.

4 Gerardi AU, Morozzi A, Bunetti P. Sull'influenza dell'esposizione cronica a vapori anestetici nell' organismo vivente. Atti Acad Anat Chir 1976;67:319-59.

5 Bardzik J, Przeździak J, Bardzik I. Immunoglobines in persons with long-term exposure to halothane. Anaesth Resus Inten Therap 1975;3:285-90.

6 Blagodarnaya OA, Popova TB, Snegova GV, et al. Comprehensive clinicohygienic and psychophysiological evaluation of the work and health of anesthetists. Gig Tr Prof Zabol 1981;6:9-13.

7 Belfrage S, Ahlgren I, Axelson S. Halothane hepatitis in an anaesthetist. Lancet 1966;ii:1466-7.

8 Klatskin G, Kimberg DV. Recurrent hepatitis attributable to halothane sensitization in an anaesthetist. $N$ Engl $J$ Med 1969;280:515-22.

9 Corbett TH. Retention of anaesthetic agents following occupational exposure. Anesth Analg 1973;52:614-8.

10 Cascorbi HF, Blake DA, Helrich M. Differences in the biotransformation of halothane in man. Anesthesiology 1970;32:119-23. 